\title{
Awareness about feeding options for infants born to HIV positive mothers and mother to child transmission of HIV in Gurage zone, south Ethiopia
}

\author{
Tefera Belachew ${ }^{1}$, Challi Jira ${ }^{2}$
}

\begin{abstract}
Background: Strategies to respond to the global HIV epidemic include preventing new infections and providing care and support to infected individuals. Prevention of Mother to Child Transmission of HIV (PMTCT) is one of the strategies given high priority.

Objective: To assess awareness of prevention of mother to child transmission of HIV.

Methods: A cross-sectional community based study was conducted in Gurage zone in October 13-28, 2004. A total of 657 participants were involved in the study. Data were collected by 12 grade completed trained enumerators using structured interviewer administered questionnaire.

Results: Overall, $84 \%$ of the respondents were aware of the recommended feeding options for infants below six months born to HIV positive women. Subjects who had good knowledge about HIV/AIDS, and those residing in the urban areas were more likely to mention the recommended feeding options, OR $(95 \% \mathrm{CI})=2.53(1.40,4.56)$ and $(95 \% \mathrm{CI})=1.83(1.13,2.96)$, respectively. Only $24 \%$ mentioned that mother-to-child transmission occurs via breast milk. Respondents with good knowledge on HIV/AIDS were twice likely to know the usefulness of VCT during pregnancy in preventing MTCT, OR $(95 \% \mathrm{CI})=1.84(1.09$, 3.09).

Conclusion: Awareness of the community about the risk of MTCT of HIV via breast milk was low. Urban residents and those who had good knowledge on HIV/AIDS were more likely to have correct knowledge on the feeding option for infants born to HIV positive mothers. [Ethiop.J.Health Dev. 2007;21(1):40-47]
\end{abstract}

\begin{abstract}
Introduction
HIV/AIDS is causing a devastating impact on the world's children (1-2). Globally, over 1,500 unborn or newborn babies are infected every day and over $90 \%$ of newly infected children are babies born to HIV-positive women, who acquire the virus at birth or through their mother's breast milk (1,3). Mother-to-child transmission (MTCT) is by far the largest source of HIV infection in children under the age of 15 , with $90 \%$ of the cases infected during pregnancy, birth, or breast-feeding (4-5). In countries where blood products are regularly screened and clean syringes and needles are widely available, it is virtually the only source infection in young children (5). Unnder-5 mortality rates showed an increase in most countries with high adult HIV prevalence (6). Though Africa accounts for only 10 percent of the world's population, one in four infants are delivered to an HIVinfected mother (7-8) and, in the absence of intervention, one in ten per year will become infected themselves (9), largely as a consequence of high fertility rates combined with very high infection rates. In Ethiopia, it is estimated that there were some 128,000 HIV positive pregnancies and 35,000 HIV positive births in 2003 (10).
\end{abstract}

The majority (63\%) of children born to HIV-infected mothers are uninfected. About $10-20 \%$ of the babies acquire the virus from their mothers during breast-feeding for the first 24 months (11-12). However, the risk may increase depending on certain situations related to the mother, the baby and the virus $(11,13)$. The rate of MTCT prior to the advent of interventions in Europe and USA was around $15-20 \%$, compared with about $30 \%$ in Africa (14). Most of this difference is a result of breast-feeding, which approximately doubles the transmission rate. In non-breast feeding populations, around two thirds of MTCT occurs around the time of delivery. The increased uptake of interventions in pregnancy has led to vertical transmission rates falling below $2 \%$ in women diagnosed prior to delivery (13). Although there are many possible explanations for this disparity, the distinct difference in the prevalence of breast-feeding among HIV-infected mothers in resource-rich versus resource-poor settings is likely implicated (14).

PMTCT is an approach towards mitigating the transmission of HIV/AIDS from mothers to their children. It focuses on the reduction of transmission of the virus to the baby in utero, during delivery and during breast-feeding by instituting optimal delivery practices and proper infant and young child feeding behaviours. There are five options for feeding babies born to HIV positive mothers: exclusive replacement feeding, wet nursing, expressing breast milk heat treating and cup feeding, and exclusive breast feeding with early cessation and exclusive replacement feeding with home modified animal milk or commercial infant formula when the replacement feeding is acceptable, feasible, affordable, sustainable and safe (AFASS) $(11,13)$. This can be

${ }^{1}$ Department of Population \& Family Health, Faculty of Public Health, Jimma University, P.O. Box 1104, Tel. 0917804072, E-mail: tefera_belachew@yahoo.com; ${ }^{2}$ Department of Health Systems Management, Faculty of Public Health, Jimma University 
realized through proper counseling of expectant mothers during the prenatal periods on the different infant feeding options (12-13).

Currently, the need to extend interventions in the PMTCT program to the mother, other children in the family and the male partner is increasingly being appreciated. UNICEF is committed to a major acceleration of "PMTCT Plus" programs, where the "Plus" package represents a comprehensive model of care that offers treatment with anti-retroviral drugs to those in need, family planning and reproductive health services, nutritional support, counseling and supportive care, and treatment of other diseases such as malaria and tuberculosis (15).

Prevention of mother to child Transmission (PMTCT) is one of the major focus areas of the National Strategic Framework for HIV/AIDS prevention. In Ethiopia, with the assistance from UNICEF, the government has also developed a national guideline on prevention of motherto-child transmission and on clinical management of HIV infection in children and adults as well as a training manual on voluntary counseling and testing (16). Awareness of the community is one of the factors affecting the uptake of PMTCT programs (17). There is paucity of information on this issue in the study areas in particular and in the country in general. This study was therefore conducted to assess the awareness of the community about the feeding options available to infants below six months born to HIV positive women and issues related to mother to child transmission of HIV.

\section{Methods}

The study was conducted in the urban and rural communities in Gurage zone South Nations, Nationalities and People's Regions (SNNPR) South Ethiopia from October 13-28, 2004. Gurage zone has a total projected population of 1,530,422, which is distributed in 12 Woredas. For the purpose of this study all permanent residents of Gurage greater that 10 years who live within 5-10 kilometers of the VCT centers in each woreda (service areas) were included in the study. Towns having a total population greater than 5,000 were taken to be urban.

A cross-sectional study design was used to assess awareness of the community about infant feeding options for HIV positive pregnant women during the first six months and mother to child transmission. The sample size was calculated using Epi Info version 2000 at the expected prevalence of awareness of infant feeding options for HIV positive woman of $50 \%$, assuming equal sample sizes for both urban and rural strata which gave a total sample size of 657 subjects to be selected from the urban and rural areas. This gives 99\% power of detecting the difference in odds ratio of 2 in awareness about
PMTCT taking urban rural differences as an exposure at confidence level of $95 \%$.

The total sample size of 657 was divided in to urban and rural strata making the number of samples to be included in the study to be 328 households from each area. Both in the urban and rural areas the total sample size 328 was divided using probability proportional to size of the kebeles involved within the strata. Then the households were selected from each kebele by using systematic sampling technique. In both rural and urban communities after identification of the sample household, one person per household of those 10 years and above was selected using a lottery method. Consent of each individual respondent was obtained before interview.

An interviewer administered Amharic version structured questionnaire was used to assess socio-demographic characteristics, infant feeding options and knowledge on the ways of mother to child transmission of HIV. The questionnaire was written in English first and then translated to Amharic and back translated into English by a third person and it was pre-tested and revised accordingly before the main study. Detailed methods on the assessment of knowledge and attitude on HIV/AIDS described elsewhere (18).

Ten 12 grade complete interviewers (5 female and 5 male) were given a thorough training on the interview techniques and the questionnaire for two days before data collection investigators verified more than 10 percent of the data during data collection. The questionnaires were checked using range and consistency check methods. The data were cleaned and coded before entering into a computer and then analyzed using SPSS for windows version 12.0. Statistical tests for significance were carried out wherever appropriate at a level of significance of $5 \%$.

Permission of the Kebele leaders was secured through an official letter from Gurage zonal HIV/AIDS secretariat. Subjects were clearly told about the benefits and harms of participating in the study through a two-way communication. Consent of subjects was secured before the initiation of data collection and subjects were assured about the confidentiality of the information they gave. To maintain confidentiality the names of subjects were not registered on the questionnaire.

\section{Results}

Out of the 657 participants included in the study, 342(52.1\%) were males and the rest 315(47.9\%) female giving a sex ratio of 1.1:1. About half (49.9\%) of the study population was from the urban areas and the rest from the rural kebeles. Over half of the respondents 336(51.1\%) were single followed by those who were married 298(45.4\%) and the majority 430(64.6\%) of them had attended schools from grade 1-12, followed by those who attended more than 12 grade $60(9.1 \%)$. The 
most frequent occupation was student (38.2\%) seconded by farmer (15.2\%) and merchant (14.6\%), respectively. The majority 550 (83.7) of the study subjects was Gurage by ethnicity followed by Amhara and Oromo. Most 372 (56.6\%) were followers of orthodox Christianity followed by Muslim 222(33.8\%). Regarding their age distribution 452(68.8\%) are in the age range between 1534 years.
Three hundred and fForty three (49.2\%) of the study participants were aware of the fact that the virus can be transmitted from mother to the baby during pregnancy and delivery. Only 158(24\%) Knew that the virus can be transmitted to through breastfeeding (Table 1).

Table 1: Ways of Mother to child transmission of HIV reported by the study participants, Gurage zone, October 2004

\begin{tabular}{lr}
\hline Ways of Mother to Child transmission of HIV (n=657) & Frequency (\%) \\
\hline During pregnancy and delivery & $323(49.2)$ \\
Breast feeding & $158(24.0)$ \\
Sharing sharp instruments & $77(11.7)$ \\
Do not know & $53(8.1)$ \\
Sharing sharp objects, pregnancy, delivery and breastfeeding & $35(5.4)$ \\
Sucking the nose of the baby right after delivery for resuscitation & $6(0.9)$ \\
\hline *More than one answer is possible
\end{tabular}

Assessment of the awareness about the usefulness of taking voluntary counseling and testing during pregnancy for the prevention of mother to child transmission of HIV showed that $74.1 \%$ reported that it is useful, followed by those who said it is not useful, and those who do not know accounting for $23.3 \%$ and $2.6 \%$, respectively (Fig $1)$.
When we control the different background variables using multivariate logistic regression model, those who had good knowledge about HIV/AIDS and PMTCT were two times more likely to state that VCT during pregnancy is useful to prevent mother to child transmission of HIV, OR $(95 \% \mathrm{CI})=1.84(1.09$, 3.09), Table 2 .

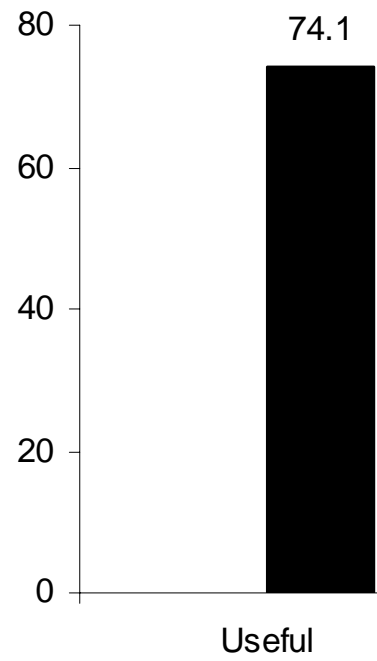

74.1

23.3

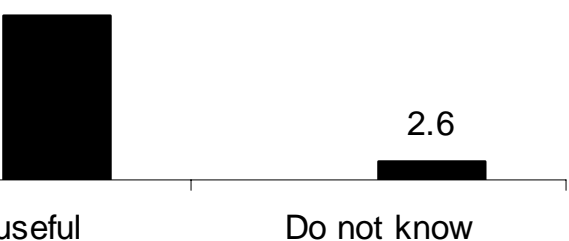

Figure 1: Knowledge of study participants about usefulness of VCT during pregnancy for prevention of mother to child transmission of HIV, Gurage zone, South Ethiopia. October 2004.

The majority (60\%) of the respondents mentioned exclusive replacement feeding as an option for feeding of infants below six months born to HIV positive mothers. The rest 24\% mentioned breast milk based options including: exclusive breast-feeding, expressed heattreated breast milk, and wet nursing. Those who mentioned mixed feeding (breast milk plus home modified animal milk or commercial infant formula) and do not know what to feed accounted for 16\% (Figure 2).
Regarding the choice of specific feeding option, most study participants mentioned cows milk (28.2\%), commercial infant formula (22.1\%), exclusive breastfeeding (16.2\%). Some $10.2 \%$ of the cases, stated both commercial infant formula and home modified animal milk (Figure 3).

Logistic regression analysis to see the association between the different background variables, knowledge

Ethiop.J.Health Dev. 2007;21(1) 
Table 2: Usefulness of VCT during pregnancy for PMTCT by socio-demographic variables, knowledge and attitude about HIVIAIDS, Gurage zone, October 2004.

\begin{tabular}{|c|c|c|c|c|}
\hline \multirow[t]{2}{*}{ Variables $(n=657)$} & \multirow[t]{2}{*}{$\mathbf{N}$} & \multicolumn{2}{|c|}{$\begin{array}{l}\text { Usefulness of VCT of pregnant } \\
\text { women for PMTCT }\end{array}$} & \multirow{2}{*}{$\begin{array}{l}\text { Adjusted OR } \\
(95 \% \mathrm{Cl})\end{array}$} \\
\hline & & Useful & $\begin{array}{l}\text { Not usefull } \\
\text { Do not know }\end{array}$ & \\
\hline \multicolumn{5}{|l|}{ Sex } \\
\hline Male & 342 & 262 & 94 & $.86(0.55,1.34)$ \\
\hline Female & 315 & 253 & 76 & 1 \\
\hline \multicolumn{5}{|l|}{ Age group } \\
\hline $10-24$ & 365 & 271 & 94 & 1 \\
\hline $25-34$ & 166 & 127 & 39 & $.73(0.41,1.27)$ \\
\hline $35+$ & 126 & 89 & 37 & $1.06(0.57,1.98)$ \\
\hline \multicolumn{5}{|l|}{ Residence } \\
\hline Urban & 328 & 234 & 94 & $1.33(0.90,1.96)$ \\
\hline Rural & 329 & 253 & 76 & 1 \\
\hline \multicolumn{5}{|l|}{ Marital status } \\
\hline Single & 336 & 255 & 81 & $1.34(0.35,5.05)$ \\
\hline Married & 298 & 216 & 82 & $1.61(0.46,5.67)$ \\
\hline Divorced & 8 & 5 & 3 & $2.09(0.31,13.68)$ \\
\hline Widowed & 15 & 11 & 4 & 1 \\
\hline \multicolumn{5}{|l|}{ Educational status } \\
\hline Illiterate & 112 & 79 & 33 & 1 \\
\hline Read \& write & 55 & 42 & 13 & $.004(0.37,1.74)$ \\
\hline Grade 1-6 & 172 & 128 & 44 & $.96(0.53,1.75)$ \\
\hline Grade $7-8$ & 121 & 89 & 32 & $1.11(0.56,2.19)$ \\
\hline Grade 9-12 & 137 & 102 & 35 & $1.07(0.54,2.12)$ \\
\hline Grade 12 \& above & 60 & 47 & 13 & $.85(0.32,2.22)$ \\
\hline \multicolumn{5}{|l|}{ Occupation } \\
\hline Student & 125 & 192 & 59 & 1 \\
\hline Farmer & 100 & 78 & 22 & $1.03(0.49,2.18)$ \\
\hline Merchant & 96 & 69 & 27 & $1.36(0.70,2.62)$ \\
\hline House wife & 106 & 72 & 34 & $1.36(0.67,2.74)$ \\
\hline House maid & 13 & 8 & 5 & $1.84(0.53,6.39)$ \\
\hline Government employee & 52 & 38 & 10 & $.94(0.35,2.67)$ \\
\hline Other ${ }^{\star \star}$ & 41 & 30 & 13 & $1.47(0.69,3.14)$ \\
\hline \multicolumn{5}{|l|}{ Knowledge about HIVIAIDS } \\
\hline Good & 571 & 433 & 138 & $1.83(1.09,3.08)^{\star}$ \\
\hline Poor & 86 & 54 & 32 & 1 \\
\hline \multicolumn{5}{|c|}{$\begin{array}{l}\text { Attitude towards preventive } \\
\text { methods of HIV }\end{array}$} \\
\hline Favorable & 576 & 433 & 143 & $1.27(0.74,2.18)$ \\
\hline Unfavorable & 81 & 54 & 27 & 1 \\
\hline
\end{tabular}

${ }^{\star P}<0.05, \quad$ ** unemployed

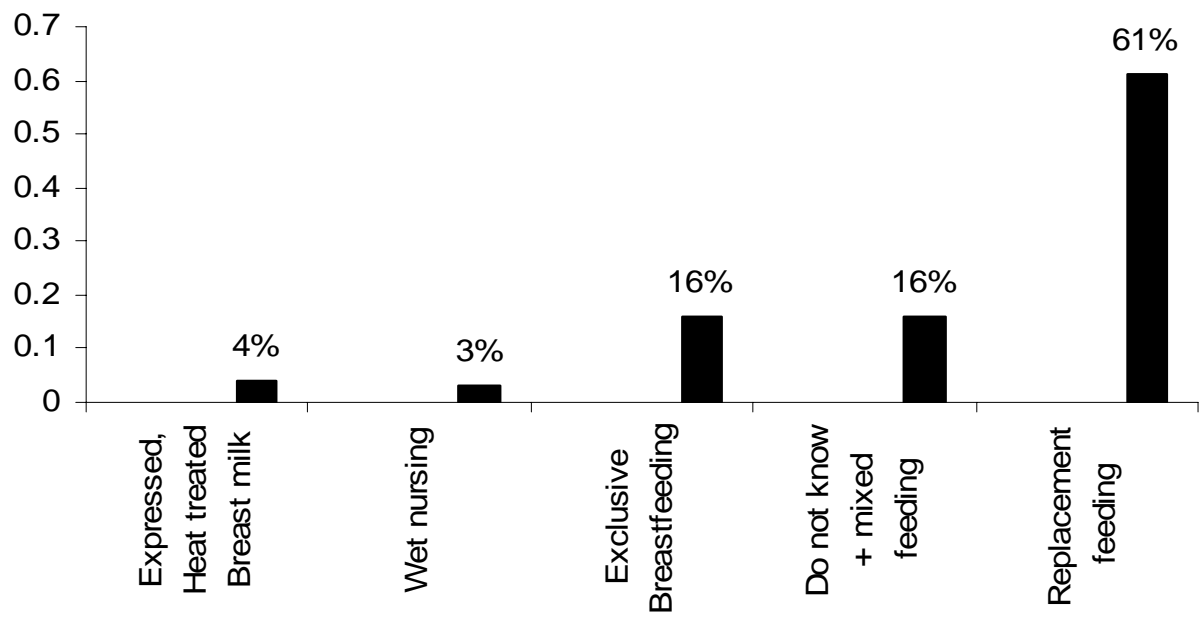

Figure 2: Feeding options fro infants below 6 months born to HIV positive mothers as reported by the study participants categorized by correct and incorrect options (do not know \& mixed feeding are incorrect options), Gurage zone, October 2004 


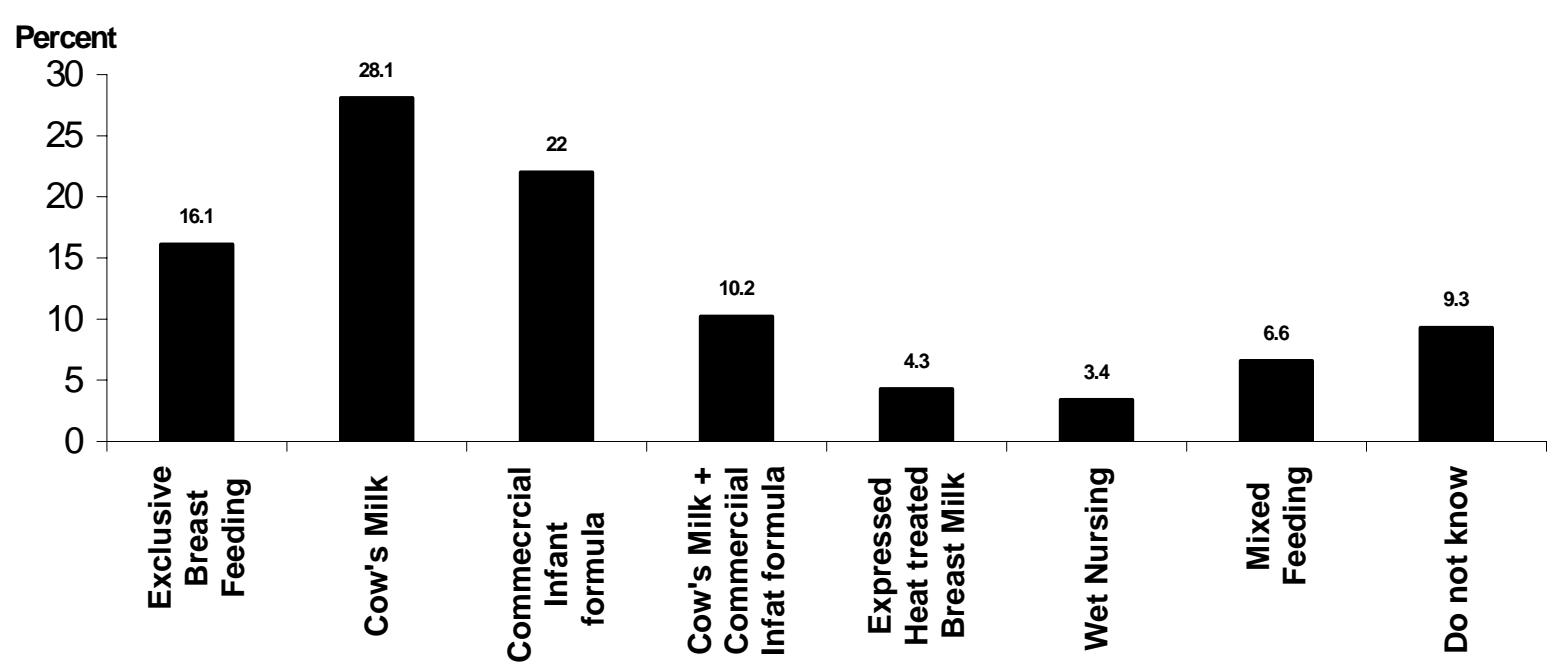

Figure 3: Specific feeding options for infants below 6 months born to HIV positive mothers as reported by the study participants, October 2004 ( $N=657)$

and attitude towards HIV showed that residence, OR $(95 \% \mathrm{CI})=1.83(1.13,2.96)$ and knowledge, on HIV/AIDS, OR $(95 \% \mathrm{CI})=2.53(1.40$, 4.56) were significantly associated with correct knowledge on the recommended feeding options. Those subjects who had good knowledge about HIV/AIDS and those residing in the urban areas were more likely to mention the right feeding options recommended by the world health organization compared to their counter parts (Table 3).

\section{Discussion}

This study assessed the benefits of PMTCT- VCT vis-àvis the different options for feeding infants blow six moths in the context of HIV/AIDS recommended by WHO. One of the most important intervention against mother to child transmission (MTCT) of HIV infection is proper counseling of mothers during the prenatal periods on the different infant feeding options to decreases the risk of acquiring the virus through breast feeding. Though the awareness of the community about the different feeding options was high (84\%), over a quarter of the respondents were not aware about the usefulness of VCT during pregnancy in preventing MTCT. The right time for making decision on the infant feeding option is before delivery, which itself is dependent on the knowledge of HIV sero- status of the mother and other issues including affordability, Acceptability, Feasibility, Sustainability and Safety (AFASS) of replacement feeding options (11-13).

The global recommendations based on these parameters is that the mother should continue to breast feed exclusively with the possible early cessation even though she is HIV positive if AFASS conditions are not fulfilled
(11,13, 19,22, 23). HIV voluntary counseling and testing (VCT) has been shown to have a role in both HIV prevention and for people with HIV infection as an entry point to care including PMTCT (17). HIV voluntary counseling and testing (VCT) services and support systems predate prevention of mother-to-child transmission (PMTCT) services and greatly influence the acceptance and use of PMTCT services (11-13).

In this study, subjects who had good knowledge of HIV/AIDS were 2.4 times more likely to state that VCT of pregnant women is useful in preventing mother to child transmission of HIV indicating the need for intensive behavior change communication to enhance the uptake of PMTCT services.

WHO's recommendations on optimal infant and young child feeding (IYCF) in the context of HIV/AIDS involves five key alternatives: Exclusive breast feeding, expressed heat treated breast milk, Wet nursing, Home modified animal milk and commercial infant formula $(11,13,19,22,23)$. Assessment of awareness of the respondents about the feeding options showed that subjects who had good knowledge of HIV/AIDS and those who were from the urban areas were 2.5 and 1.8 times more likely to be aware of the optimal infant feeding practices in the context of HIV/AIDS, respectively $(\mathrm{P}<0.05)$. Knowledge of $\mathrm{HIV} / \mathrm{ADS}$ contributes to the waysan increase in the awareness of MTCT enabling the respondents to know the different feeding option for infants in the context of HIV/AIDS. Additionally, subjects from the urban areas are more accessible to information via mass media and other sources of information.

Ethiop.J.Health Dev. 2007;21(1) 
Table 3: Awareness of recommended feeding options for infants below six months born to HIV positive women by socio-demographic variables and knowledge and attitude about HIVIAIDS, Gurage Zone, October 2006

\begin{tabular}{|c|c|c|c|c|}
\hline \multirow[t]{2}{*}{ Variables $(n=657)$} & \multirow[t]{2}{*}{$\mathbf{N}$} & \multicolumn{2}{|c|}{$\begin{array}{l}\text { Knowledge on recommended } \\
\text { Feeding option for infant }<6 \\
\text { months }\end{array}$} & \multirow[t]{2}{*}{$\begin{array}{l}\text { Adjusted OR } \\
(95 \% \mathrm{Cl})\end{array}$} \\
\hline & & Correct $¥$ & Incorrect§ & \\
\hline \multicolumn{5}{|l|}{ Sex } \\
\hline Male & 342 & 289 & 53 & $.76(0.44,1.30)$ \\
\hline Female & 315 & 264 & 51 & 1 \\
\hline \multicolumn{5}{|l|}{ Age group } \\
\hline $10-24$ & 365 & 304 & 61 & 1 \\
\hline $25-34$ & 166 & 145 & 21 & $1.03(0.51,2.11)$ \\
\hline $35+$ & 126 & 104 & 22 & $1.44(0.65,3.18)$ \\
\hline \multicolumn{5}{|l|}{ Residence } \\
\hline Urban & 328 & 269 & 59 & $1.82(1.12,2.96)^{\star}$ \\
\hline Rural & 329 & 284 & 45 & 1 \\
\hline \multicolumn{5}{|l|}{ Marital status } \\
\hline Single & 336 & 276 & 60 & 1 \\
\hline Married & 298 & 258 & 40 & $.66(0.34,1.30)$ \\
\hline Divorced & 8 & 8 & 0 & $.00(0.00)$ \\
\hline Widowed & 15 & 11 & 4 & $1.11(0.27,4.49)$ \\
\hline \multicolumn{5}{|l|}{ Educational status } \\
\hline Illiterate & 112 & 87 & 25 & 1 \\
\hline Read \& Write & 55 & 50 & 5 & $.37(0.13,1.09)$ \\
\hline Grade 1-6 & 172 & 144 & 28 & $.70(0.34,1.41)$ \\
\hline Grade 7-8 & 121 & 104 & 17 & $.64(0.28,1.46)$ \\
\hline Grade $9-12$ & 137 & 114 & 23 & $.72(0.32,1.63)$ \\
\hline Grade $12 \&$ above & 60 & 54 & 6 & $.62(0.18,2.15)$ \\
\hline \multicolumn{5}{|l|}{ Occupation } \\
\hline Student & 251 & 210 & 4.1 & 1 \\
\hline Farmer & 100 & 79 & 21 & $1.93(0.82,4.54)$ \\
\hline merchant & 96 & 85 & 11 & $.67(0.28,1.58)$ \\
\hline House wife & 106 & 92 & 14 & $.77(0.31,1.91)$ \\
\hline House maid & 13 & 10 & 3 & $1.19(0.26,5.29)$ \\
\hline Government employee & 52 & 45 & 3 & $.38(0.08,1.73)$ \\
\hline Other $^{1}$ & 41 & 32 & 11 & $1.80(0.78,4.14)$ \\
\hline \multicolumn{5}{|l|}{$\begin{array}{l}\text { Knowledge about HIVIAIDS } \\
\text { and PMTCT }\end{array}$} \\
\hline Good & 571 & 491 & 80 & $2.53(1.40,4.56)^{\star \star}$ \\
\hline Poor & 86 & 62 & 24 & 1 \\
\hline \multirow{2}{*}{\multicolumn{5}{|c|}{$\begin{array}{l}\text { Attitude toward preventive } \\
\text { methods of HIV including } \\
\text { PMTCT }\end{array}$}} \\
\hline & & & & \\
\hline Favorable & 576 & 486 & 90 & $.74(0.37,1.49)$ \\
\hline Unfavorable & 81 & 67 & 14 & 1 \\
\hline
\end{tabular}

In this study, some $16.2 \%$ stated exclusive breastfeeding during the first six months as an option for feeding of infants born to HIV positive women. Breastfeeding is associated with a significant additional risk of HIV transmission from mother to child as compared to nonbreastfeeding. The risk of MTCT of HIV through breastfeeding appears to be greatest during the first months of infant's life but persists as long as breastfeeding continues. Half of the breastfeeding-related infections may occur after 6 months with continued breastfeeding into the second year of life (18).
In untreated women who continue breastfeeding after the first year, the absolute risk of transmission through breastfeeding is $10-20 \%(11,13,19,22,23)$. This risk depends on clinical factors and may vary according to pattern and duration of breastfeeding. The transmission of HIV virus to the infant through breast milk is much less efficient than transmission through maternal blood and other fluids present during birth. However, the period of exposure to breast milk in patterns of breastfeeding, which was common in the study community, can be as long as a year or more, allowing a much longer risk of exposure. The presence of cracked nipples or mastitis in 
breastfeeding mothers can increase the transmission of virus to the baby, and it is important to inform mothers, families and providers of this easily avoided or treated route of transmission (25).

There are evidences that this risk has been reduced dramatically by interventions focusing on optimal infant and young child feeding in the context of HIV/AIDS (13).

Awareness of the community about the benefits of the PMTCT programs affects its programmatic uptake the resultant benefit in curbing the problem of MTCT (17). PMTCT programs after delivery involve, promotion of exclusive breastfeeding with early cessation, or exclusive replacement feeding (19-21) and promotion of safe sex for woman and all partners; and to partners' sexual networks to avoid infection/reinvention re-infection during breast feeding $(17,23,24$,$) .$

Each intervention has associated behaviors that involve individual pregnant women and new mothers, family members, and professional and traditional healthcare providers. While each element of the set of interventions/behaviors exerts its own effect on the reduction of MTCT, optimal results occur when the full set of interventions and the associated behaviors are put into practice (25).

In this study awareness of the community on mother to child transmission via breast-feeding was $24 \%$, which is very low, compared to reports of a study in Ndola, Zambia which was $57-77 \%(26)$, but higher than reports from Uganda, which showed that $19 \%$ of pregnant women knew MTCT could occur during breastfeeding (27). The disparity between high level of awareness on feeding option and low level of knowledge on the risk of MTCT via breast milk is due to the fact that the majority (61\%) of the respondents stated MTCT to occur during pregnancy and delivery. During the post natal period the route transmission mentioned was also sharing of sharp objects between the mother and the baby and sucking of the nose of the bay after delivery, which is a traditional resuscitation technique in the study community as observed from the FGD findings. So, the intent of using replacement feeding was also partly to avoid the contact between the mother and the baby if not only to avoid breastfeeding.

Creating widespread community awareness of the full set of behaviors necessary to prevent MTCT is an essential step to improve participation in and adherence to interventions that are part of PMTCT Programs. In many communities, even where PMTCT Programs are active, knowledge about mother-to-child transmission is low. Awareness of the mechanisms through which HIV can be transmitted from mother to child is variable at community level. Creating community awareness of the importance of improved practices to reduce MTCT is also important. Improved practice cannot be targeted only at health professionals. TBAs, families and communities must be made aware of the factors contributing to MTCT and how to change practices accordingly (17).

According to this study $61 \%$ of the respondents stated that HIV positive women should give replacement foods to their baby. In developing countries, replacement feeding carries an increased risk of morbidity and mortality associated with malnutrition and associated with infectious disease other than HIV. This is especially high in the first 6 months of life and decreases thereafter $(19,22,24)$. The local environment and the individual woman's situation affect the risk and feasibility of replacement feeding. When we come to the individual women, counseling of the infant feeding option need to asses the AFASS conditions very rigorously before recommending replacement foods as an option $(11,13$, 19).

It has been documented that mixed feeding of infants will predispose them to increased risk of mother to child transmission (13, 19,22, 23). Mixed feeding was also observed to result in higher rate of mortality due to diarrheal diseases (28), which makes replacement feedings unjustifiable in this context. In this study, $16 \%$ of the respondents said they will give mixed feeding or do not know what type of feeding is recommended for infants below six months born to HIV positive women, which needs public health intervention to increase their awareness.

In conclusion: though the majority (84\%) community had correct knowledge on feeding options for infants below six months born to HIV positive mothers, over a quarter of the respondents did not have awareness on usefulness VCT of pregnant women in preventing mother to child transmission of HIV. Awareness of the community about the risk of mother to child transmission of HIV via breast milk was low, as only $24 \%$ mentioned MTCT via breast milk. The majority of the study participants stated replacement feeding as an option for infants below six months born to HIV positive women with or without AFASS. Urban residents and those who had good knowledge on HIV/AIDS were more likely to have correct knowledge on the feeding option for infants born to HIV positive mothers.

Intensive Information, education \& communication to raise the awareness of the community on the risk MTCT via breast-feeding, Usefulness of VCT during pregnancy and AFASS issues for replacement feeding is recommended to promote the uptake of PMTCT services and enhance their effectiveness in Gurage zone. 


\section{Acknowledgments}

We highly appreciate the study community, the data collectors and Gurage Zonal HIV/AIDS secretariat Mostmost specially that of Mr. Kinfe Girma and Mr. Mifta Altaye.

\section{Reference}

1. AVERT. An international AIDS Charity. Avert.org Worldwide HIV/AIDS epidemic statistics, 2005, http://www.avert.org/worlstatinfo.htm.

2. Neff Walker, Bernhard Schwartländer, Jennifer Bryce. Meeting international goals in child survival and HIV/AIDS, THE LANCET, April 30, 2002, published online, http://image.thelancet.com/extras/01art9188web.pdf.

3. USAID. Integrating Prevention-of-Mother-to-ChildTransmission into Existing African Health Care Systems 1300 Pennsylvania Avenue NW Washington, DC 20523-3600 www.usaid.gov, Kenya and Zambia, May 2003.

4. Kapoor A, Kapoor A, Vani SN. Prevention of mother to child transmission of HIV. Indian J Pediatr [serial online] 2004 [cited 2007 Mar 14]; 71:247251.

5. Groves T. Reducing the risk of transmitting HIV from mother to child in Africa, BMJ, 2004, 12.

6. Adetunji J. Trends in under-5 mortality rates and the HIV/AIDS epidemic, Bulletin of the World Health Organization, 2000; 78:1200-1206.

7. Zambia: socio-demographic prevalence patterns and indications of trends among childbearing women. AIDS, 1997; 11:339-345.

8. 8.Stringer J, Sinkala M, Stout J, Acosta EP, Chapman V, Kumwenda, et al. Comparison of two strategies for administering nevirapine to prevent perinatal HIV transmission in high-prevalence, resource-poor settings. J AIDS, in press, 2003.

9. 9.De Cock KM, Fowler MG, Mercier E, de Vincenzi I, Saba J, Hoff E, et al. Prevention of mother-to-child HIV transmission in resource-poor countries: translating research into policy and practice. JAMA, 2000; 283:1175-1182.

10. MOH. AIDS in Ethiopia, Disease prevention and control Department, Federal Ministry of Health. June 2004.

11. Elizabeth A. Ellen G. Piwoz. Prevention Of MotherTo-Child Transmission Of HIV In Africa: Practical Guidance For Programs, June 2001.

12. Elizabeth A. Ellen G. Piwoz,. Prevention Of MotherTo-Child Transmission Of HIV In Asia: Practical Guidance For Programs, June 2002

13. Goedert JJ, Gray L, Korber BT, et al. Perinatal transmission of HIV-1 from pregnant women with RNA viral load less than 1000 copies/ml [abstract 517]. 8th Conference on Retroviruses and Opportunistic Infections, Chicago, 2001;8.
14. M Sharland, D M Gibb and G Tudor-Williams. Advances in the prevention and treatment of paediatric HIV infection in the United Kingdom, Sex Transm Inf; 2003; 79:53-55.

15. United Nations Children's Fund (UNICEF). HIV/AIDS: PMTCT-Plus, Unite Against AIDS, Information Sheet, Last Updated, July 2006.

16. UNICEF. UN Special Session HIV/AIDS: Back ground Information: HIV/AIDS, 2001, PMTCT Pilot Projects in Ethiopia, UNICEF, June 2001.

17. UNAIDS. Voluntary counseling and testing (VCT) Technical Update, 2000.

18. Belachew T, Jira C, Tushune K. Knowledge, attitude and practice of voluntary confidential counseling \& testing (VCCT) in Gurage Zone, SNNPR, and South Ethiopia, Ethiopian Journal of Health SC. 2005; 15(2): 119-38.

19. World Health Organization. HIV and infant feeding: A guide for health-care managers and supervisors, WHO, 2003.

20. WHO \& PAHO. Guiding Principles For Complementary feeding of a breast fed child, December 10-13, 2001.

21. Federal MOH. National Strategy For Infant And Young Child Feeding, April 2004.

22. World Health Organization, Infant and young child nutrition, Global strategy on infant and young child feeding, Fifty-Fifth World Health Assembly A55/15, Provisional agenda item 13.1016 April 2002.

23. WHO.HIV and infant feeding: framework for priority action, WHO 2003.

24. The LINKAGES /AED Project. Infant Feeding Options, in the Context of HIV, April 2004.

25. Mona Moore. A Behavior Change Perspective, on Integrating PMTCT and, Safe Motherhood Programs, A Discussion Paper, The CHANGE Project AED/The Manoff Group, Washington, D.C., March 2003.

26. Population Council. Ndola Demonstration Project: A Midterm Analysis of Lessons Learned. Horizons Project and Linkages Project, January 2003.

27. Kigozi, G. et al. Knowledge, attitudes, beliefs and practices (KABP) about nevirapine and prevention of MTCT of HIV in a rural resource poor community, Rakai Uganda. Presented at XIV International AIDS Conference, Barcelona, 2002; 7`12.

28. Victora CG. Infant feeding and deaths due to diarrhea. A case-control study. Am J Epidemiol. 1989; 129(5): 1032-41. 